\title{
Análise de trilha dos atributos físicos de milho (Zea mays L.) em sistema de cultivo convencional
}

\author{
Path analysis of physical attributes in maize (Zea mays $\mathrm{L}_{\text {. }}$ ) under conventional cultivation system \\ Análisis de rastros de los atributos físicos del maíz (Zea mays L.) en sistema de cultivo convencional
}

Recebido: 02/12/2020 | Revisado: 10/12/2020 | Aceito: 30/12/2020 | Publicado: 03/01/2021

Luana da Silva Pinheiro

ORCID: https://orcid.org/0000-0002-1192-989X Universidade Federal Rural da Amazônia, Brasil E-mail: luulupinheiro@hotmail.com

Rodrigo Cruz Silva

ORCID: https://orcid.org/0000-0003-1029-0323 Universidade Federal Rural da Amazônia, Brasil

E-mail: rodriigocruz@hotmail.com

Regiane da Conceição Vieira

ORCID: https://orcid.org/0000-0001-9752-6196

Universidade Federal Rural da Amazônia, Brasil E-mail: regiane.vieira.c11@gmail.com

Rodrigo Oliveira Aguiar

ORCID: https://orcid.org/0000-0003-0390-928X

Universidade Federal Rural da Amazônia, Brasil E-mail: rodrigoagro08@hotmail.com

Maiane Rodrigues do Nascimento ORCID: https://orcid.org/0000-0002-4170-5694

Universidade Federal do Maranhão, Brasil

E-mail: maianerodrigues707@gmail.com

Mateus Monteles Vieira

ORCID: https://orcid.org/0000-0003-3756-8946

Universidade Federal do Maranhão, Brasil

E-mail: mateusmv7@gmail.com

Raul Fortes Sousa

ORCID: https://orcid.org/0000-0003-1820-0572

Universidade Federal do Maranhão, Brasil

E-mail: raul_forttes@hotmail.com

Job Teixeira de Oliveira

ORCID: https://orcid.org/0000-0001-9046-0382

Universidade Federal do Mato Grosso do Sul, Brasil

E-mail: job.oliveira@hotmail.com

José Nilton da Silva

ORCID: https://orcid.org/0000-0003-0298-9126

Universidade Federal Rural da Amazônia, Brasil

E-mail: jose.nilton@ufra.edu.br

Vicente Filho Alves Silva

ORCID: https://orcid.org/0000-0003-2396-6986

Universidade Federal Rural da Amazônia, Brasil

E-mail: vicente.silva@ufra.edu.br

Priscilla Andrade Silva

ORCID: https://orcid.org/0000-0002-2774-3192

Universidade Federal Rural da Amazônia, Brasil

E-mail: priscilla.andrade@ufra.edu.br

\begin{abstract}
Resumo
O cultivo da cultura do milho (Zea mays L.) tem uma extrema importância econômica e social, pois ele é cultivado em praticamente todas as partes do planeta. O objetivo desse trabalho foi avaliar os atributos físicos da espiga, que melhor descrevem a massa da espiga do milho. O experimento teve sua condução realizada nas comodidades da área experimental do centro tecnológico da Agricultura Familiar (CETAF), localizado no município de Parauapebas- PA, pertencente a mesorregião Sudeste do Pára. Análise de trilha foi realizada usando o software GENES, responsável por detalhar a relação entre uma variável e outra. De forma direta, que os atributos massa total da espiga e massa de grãos da espiga, foram os atributos que melhor representam a massa da espiga. De forma indireta, observamos que a massa total da espiga, influencia significativamente a massa dos grãos da espiga.
\end{abstract}

Palavras-chave: Milho; Multicolinearidade; Análise de trilha. 


\begin{abstract}
The cultivation of maize (Zea mays L.) has extreme economic and social importance, as it is cultivated in practically all parts of the planet. The objective of this work was to evaluate the physical attributes that best describe the mass of the corn ears. The experiment was conducted in the facilities of the experimental area of the technological center of family farming (CETAF), located in the southeast region of Pára, in the municipality of Parauapebas. Path analysis was performed using the GENES software, responsible for detailing the relationship between one variable and another. Directly, that the attributes total mass of the ear and mass of grains of the ear, were the attributes that best represent the mass of the ear. Indirectly, we observed that the total mass of the ear significantly influences the mass of the ear grains.
\end{abstract} Keywords: Maize; Multicollinearity; Track analysis.

\title{
Resumen
}

El cultivo de maíz (Zea mays L.) tiene una importancia económica y social extrema, ya que se cultiva en prácticamente todas las partes del planeta. El objetivo fue evaluar los atributos físicos que mejor describen la masa de la mazorca de maíz. El experimento se realizó en las instalaciones del área experimental del Centro Tecnológico de Agricultura Familiar (CETAF), ubicado en el municipio de Parauapebas-PA, perteneciente a la región sureste de Pára. El análisis de seguimiento se realizó mediante el software GENES, responsable de detallar la relación entre una variable y otra. Directamente, que los atributos masa total de la oreja y masa de granos de la oreja, eran los atributos que mejor representaban la masa de la oreja. Indirectamente, observamos que la masa total de la mazorca influye significativamente en la masa de los granos de la mazorca.

Palabras clave: Maíz; Multicolinealidad; Análisis de pistas.

\section{Introdução}

O cultivo da cultura do milho (Zea mays L.) tem uma extrema importância econômica e social, pois ele é cultivado em praticamente todas as partes do planeta, esse cereal está presente em diversas situações do cotidiano, entre elas a alimentação humana, bem como a animal, e não apenas para cunho alimentício, mas também está envolvido em abastecimento de energia como um biocombustível. (Embrapa, 2019).

A produção do cereal alcançará recorde de 102,5 milhões de toneladas, sinalizando a importância da cultura para economia do país (Conab, 2020). A previsão de exportação, por outro lado, permanece inalterada e segue previsto um montante total de 34,5 milhões de toneladas de milho a ser exportado no atual ciclo.

A cultura do milho possui características de estudo bastante instigante, pois ela oferece base para avanços futuros. A comoditie, ganhou espaço em território nacional, da mesma forma que todas as outras culturas tradicionais, que utilizavam tecnologia menos desenvolvida, buscando terras ainda não agricultáveis, bem como a fertilidade natural dos solos. (Alves et al., 2019)

A avaliação de propriedades de atributos físicos é uma alternativa para o melhoramento da qualidade do desempenho das produções de milho em grande escala, pois a partir dessas características pode-se almejar a produtividade. Alguns desses atributos físicos correspondem a características do peso da espiga, espiga com palha ou sem tamanho da espiga, aos grãos, peso e tamanho. E dessa forma é possível discutir como esses atributos são influenciados pela interação dos fatores sistema de cultivo e cultivares. (Pinho et al., 2008).

Uma das ferramentas desenvolvidas para se trabalhar com essas e muitas outras variáveis é a análise de trilha (Path analysis), essa vertente tem como objetivo, explicar as ações diretas e indiretas, de diversas variáveis que não dependem de uma variável dependente (básica), onde a aferição dos dados são adquiridos através de equações de regressão, enquadrando a variáveis (Cruz et al., 2013).

Para assegurar uma boa produtividade na cultura do milho, é essencial que as espigas expressem atributos físicos significativamente positivos, para que se enquadrem nos parâmetros comerciais, sendo eles um bom emparelhamento e também o peso (Favarato et al., 2016). Esses atributos podem ser constatados tanto pela quantidade de grãos quanto pelo tamanho de suas espigas, determinando assim seu fator de escolha na comercialização (Vieira et al., 2010). 
Dessa forma o trabalho objetivou avaliar os atributos físicos da espiga, que melhor descrevem a massa da espiga do milho.

\section{Materiais e Métodos}

O presente estudo trata-se de uma pesquisa experimental de ordem qualitativa, com obtenção de dados numéricos em laboratório, aos quais permitiram avaliar os melhores atributos que representam a massa dos grãos de milho de diferentes cultivares por meio de análises estatísticas (Pereira et al., 2018).

O experimento foi conduzido nas comodidades da área experimental do Centro Tecnológico da Agricultura Familiar (CETAF) (Figura 1), no período de 03 de março a 20 de junho de 2019. O Centro está localizado na mesorregião Sudeste do Pará, no Município de Parauapebas (0603’30” de latitude Sul; 4955’15” de longitude Oeste), conforme dados de GPS portátil (Modelo Trex 10, Marca Garmin).

Figura 1 - Mapa da localização da área de estudo, município de Parauapebas.

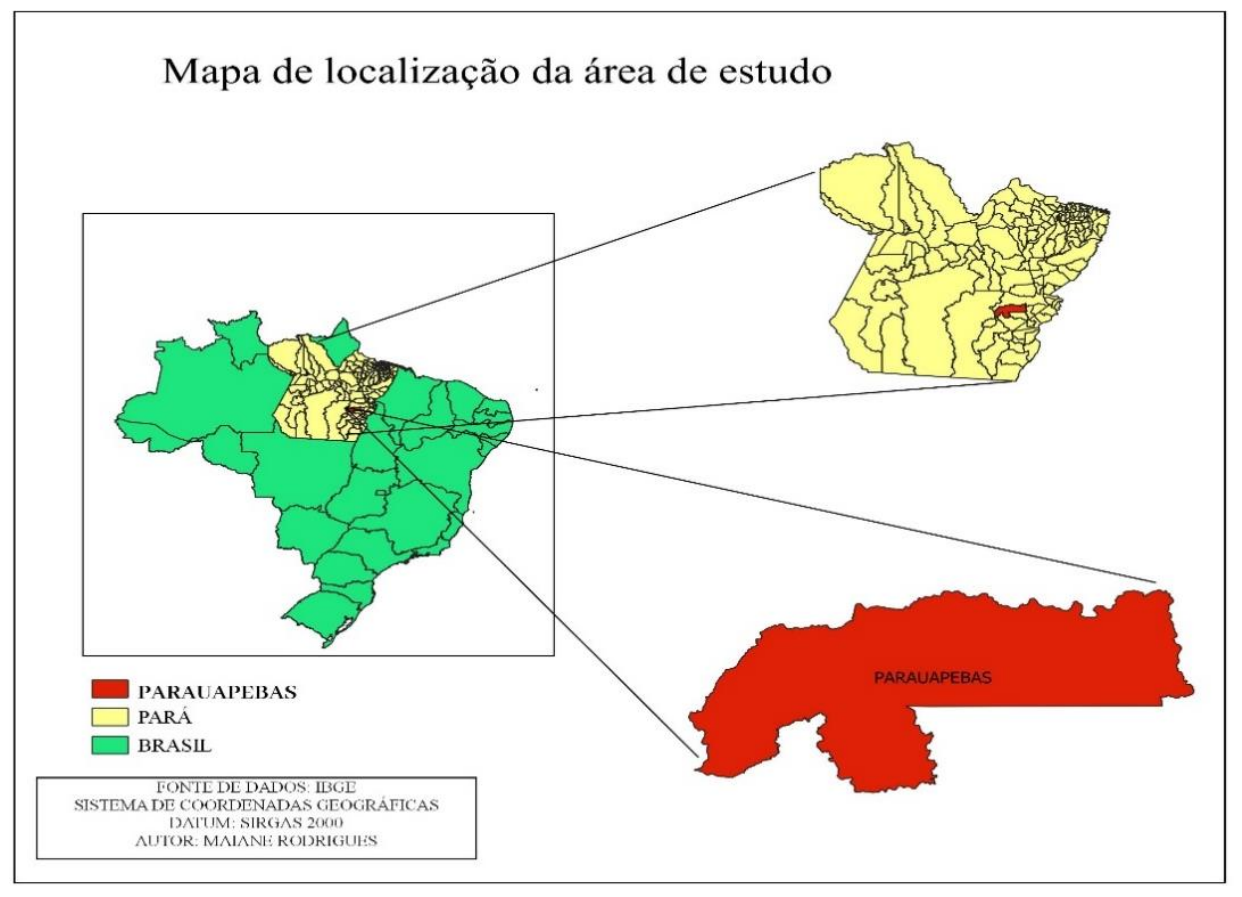

Fonte: Autores.

O solo foi classificado como um Argissolo Vermelho-Amarelo (EMBRAPA, 2018) e o clima da região caracterizado como equatorial super úmido, de acordo com a classificação de Köppen, no limite de transição para o Aw (clima tropical chuva de verão). Em relação à temperatura média, média anual é $26^{\circ} \mathrm{C}$, e as médias das máximas e mínimas, respectivamente, em torno de $33{ }^{\circ} \mathrm{Ce} 22{ }^{\circ} \mathrm{C}$. O total pluviométrico anual é de aproximadamente 1827 milímetros, com o período mais chuvoso se estendendo de dezembro a maio.

Foi empregado o plantio convencional, sendo este realizado pelo processo de duas arações e uma gradagem. A semeadura foi realizada no dia 3 de março de 2019, com o auxílio de uma semeadora adubadora. A adubação de semeadura consistiu na adição de $350 \mathrm{~kg}$ de NPK, com proporções correspondentes a $110 \mathrm{Kg}$ de Nitrogênio, $150 \mathrm{~kg}$ de fosforo, e $90 \mathrm{Kg}$ de Potássio, com mais $50 \mathrm{~kg}$ de micronutrientes.

Em se tratando das cultivares de milho que foram avaliadas nove variedades. O espaçamento definido seguiu o enquadramento do espaçamento entre fileira de 0,2 m entre plantas e 0,7 m entre fileiras, as cultivares avaliadas foram: C1-7742, 
C2- EXP.61, C3-6520, C4-713265, C5- EXP.83, C6-7641, C7-7132, C8- EXP.88, C9-774265. O experimental foi conduzido em faixas e o delineamento experimental considerado para o experimento foi com nove tratamentos e cinco repetições.

As análises de caracterização física e do rendimento dos grãos de milho foram realizadas no Laboratório de Análises de Alimentos da Universidade Federal Rural da Amazônia, no Campus de Parauapebas, Pará, localizada nas coordenadas geodésicas 06²' $58^{\prime}$ ' S latitude e 4951'19' 'W longitude, com altitude de 197 m (conforme dados de GPS portátil, Modelo Trex 10, Marca Garmin). Para a realização da caracterização física e análises das espigas das cultivares, levou- se em consideração uma amostra de 100 espigas de cada parcela útil de cada cultivar, totalizando nesse caso 900 espigas para concretizar a caracterização física. Onde esse processo teve como objetivo determinar as medidas dos comprimentos das espigas com para (CEP), com auxílio de um paquímetro analítico metálico $300 \mathrm{~mm}$ com precisão de $0,01 \mathrm{~mm}$ e uma trena.

Para a análise de rendimento dos grãos de milho, consistiu na separação dos grãos, sendo este procedimento realizado pelo auxílio de uma faca de material inoxidável, a palha foi removida manualmente, e os rendimentos foram determinados por meio das suas correspondentes massas, utilizando uma balança semi-analitica (Modelo ARD110, Marca OHAUS Adventurer).

Para a realização da aquisição dos grãos foi realizado uma série de procedimentos que consistiu nas seguintes etapas: assim que as espigas sem palhas foram selecionadas e devidamente lavadas, sendo essas imersas em uma solução composta de hipoclorito de sódio $(\mathrm{NaCl})(200 \mathrm{mg} / \mathrm{L})$, esse procedimento durou cerca de 15 minutos, e novamente repetido dessa vez as espigas foram mergulhadas em água, separadamente.

Posteriormente as amostras de grãos foram extraídas das respectivas espigas de forma manual, e depois embaladas em sacos plásticos de material polietileno de $1 \mathrm{Kg}$, as mesmas foram congeladas e armazenadas a temperatura correspondente a -20 ${ }^{\circ} \mathrm{C}$ para utilização em análises posteriores.

Os resultados das análises físicas das espigas, e dos grãos de milho foram avaliados através da estatística descritiva, utilizando-se o software RBio (Bhering, 2017). Este software também determinou a rede de correlações e avaliada a multicolinearidade entre os atributos. A análise estatística dos dados teve embasamento no valor médio das observações realizadas em nove cultivares de híbridos de milho, foi realizada para determinar a correlação e regressão de características na produção do milho (Shikha et al., 2020).

A Análise de trilha foi realizada usando o software GENES (Cruz, 2013), responsável por detalhar a relação entre uma variável e outra, fazendo com que as multicolinearidades sejam eliminadas, alcançando sua aplicabilidade. A Figura 2 apresenta as relações estudadas entre os atributos, sendo a massa da espiga (ME) a variável principal em relação aos demais atributos. 
Figura 2 - Relação entre os atributos na análise de trilha: comprimento (CO), diâmetro da base (DB), diâmetro do meio (DM), diâmetro da ponta (DP), massa da casca (MC), massa dos grãos da espiga (MG), massa da espiga (ME) e massa total da espiga (MT).

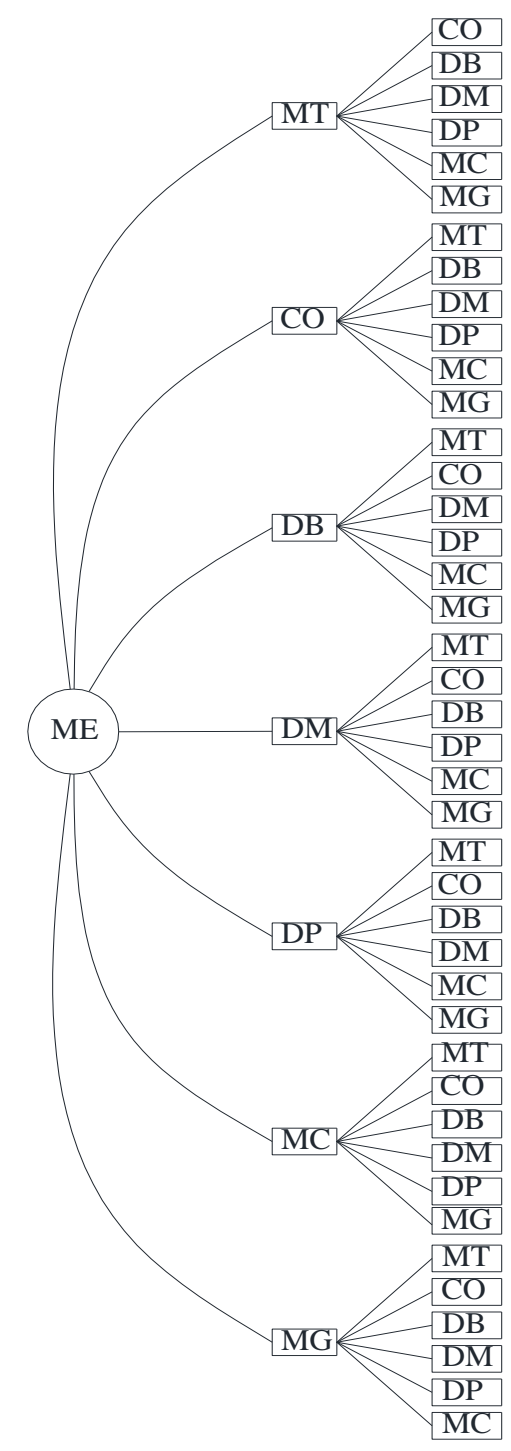

Fonte: Autores.

\section{Resultados e Discussão}

A estatística descritiva apresentada na Tabela 1 levou em consideração a produção das espigas grãos e palha, que é a massa total da espiga (MT); comprimento da espiga, (CO); diâmetro da base, (DB); diâmetro do meio da espiga, (DM); diâmetro da ponta da espiga, (DP); massa da casca da espiga, (MC); massa da espiga, (ME) e massa dos grãos, (MG) de acordo com a variedade do milho estudado no experimento correlacionam com os demais atributos. 
Tabela 1 - Estatísticas descritivas a respeito dos dados analisados. MT - massa total da espiga, CO - comprimento da espiga, DB- diâmetro da base, DM- diâmetro do meio da espiga, DP- diâmetro da ponta da espiga, MC- massa da casca, ME- massa da espiga, MG- massa dos grãos.

*D.P- desvio padrão

\begin{tabular}{ccccc}
\hline Cultivar & Mínimo & Média & Máximo & D.P* \\
\hline MT (g) & 107,00 & 180,87 & 282,00 & 38,55 \\
CO (cm) & 20,50 & 27,97 & 39,00 & 3,33 \\
DB (cm) & 1,08 & 2,79 & 5,03 & 0,67 \\
DM (cm) & 2,12 & 4,67 & 5,87 & 0,48 \\
DP (cm) & 1,01 & 2,38 & 4,76 & 0,82 \\
MC (g) & 12,00 & 41,45 & 83,00 & 13,45 \\
ME (g) & 69,00 & 134,33 & 226,00 & 31,36 \\
MG (g) & 21,00 & 75,26 & 99,40 & 17,30 \\
\hline
\end{tabular}

Fonte: Autores.

A Massa total da espiga apresentou um bom resultado com um valor máximo acima do considerado mínimo no mercado. E da mesma forma, o comprimento total revelou uma média de $39 \mathrm{~cm}$. Este valor mostra que a maioria das espigas obtiveram um percentual de desenvolvimento atrativo para os parâmetros produtivo de venda, onde espigas grandes são vendidas in natura e esses aspectos influenciam na preferência do consumidor. Outra variável comercial que pode ser observada é a massa da casca que também é vista como um fator de aproveitamento no mercado apresentando valor médio de 41,45 g o que seria uma característica adequada, considerando que em muitas vezes são utilizadas na indústria de pamonharia, que necessita de palha para confecção da pamonha (Pinho et al., 2008).

O diâmetro da espiga sem casca também teve um bom desempenho, com uma média de 4,67 cm, isso quer dizer que é superior à média comercial, pois espigas sem palha e com diâmetro médio superior a 4,00 cm, granadas e isentas de injúrias causadas por insetos praga e doenças, são consideradas produtos de padrão comercial (Moreira et al., 2010).

Resultados parecidos com os de Santos et al. (2015), que obteve a média do diâmetro de espigas entre 46,68 mm e 47,72 mm em cultivares de milho verde em sistemas convencionais e orgânicos. Observou-se que o diâmetro e o comprimento das espigas são variáveis de grande relevância quando se trata de comercialização por unidade ou bandeja. De modo equivalente, Fernandes et al. (2017), obteve diâmetro máximo de 4,49 cm com a influência de parcelamento de doses de nitrogênio (N).

Uma das variáveis que também apresentou um bom desenvolvimento foi a de massa de grãos, com uma máxima de 99,4 g. Em uma parcela de amostras das espigas, a massa dos grãos, alcançou um valor de quase 100,0 g, uma resposta interessante para diversas finalidades de mercado, principalmente se o objetivo for excepcionalmente os grãos de milho verde, onde esses podem ser vendidos e enlatados, dessa forma o resultado foi satisfatório levando em consideração a proporção da produtividade.

Nos estudos feitos por Fernandes et al. (2017), a máxima obtida em massa de grãos foi de 287,65 g para massa de 1000 grãos. Essa produtividade está relacionada à interação de nitrogênio $(\mathrm{N})$ e fosforo $(\mathrm{P})$ usado para obter crescimento e produtividade dos grãos. 
A Figura 3 representa a rede de correlações e nela, a massa de grãos se correlaciona de forma negativa com diâmetro da ponta da espiga demonstrando que os grãos na ponta da espiga tendem a terem o seu desenvolvimento inferior em relação ao meio da espiga. Atributos físicos de peso médio de massa total de espigas, bem como no caso das sem palha são os principais fatores levados em consideração para percentual de produtividade de espigas comerciais, da mesma forma que comprimento e diâmetro médios de espigas comerciais sem palha (Favarato et al., 2016).

Figura 3 - Rede de correlação entre os atributos físicos da cultivar de milho: massa total da espiga, (MT); comprimento total da espiga com casca (CO), diâmetro da base, (DB); diâmetro do meio da espiga, (DM); diâmetro da ponta da espiga, (DP); massa da palha (MC); massa da espiga, (ME); massa dos grãos (MG).

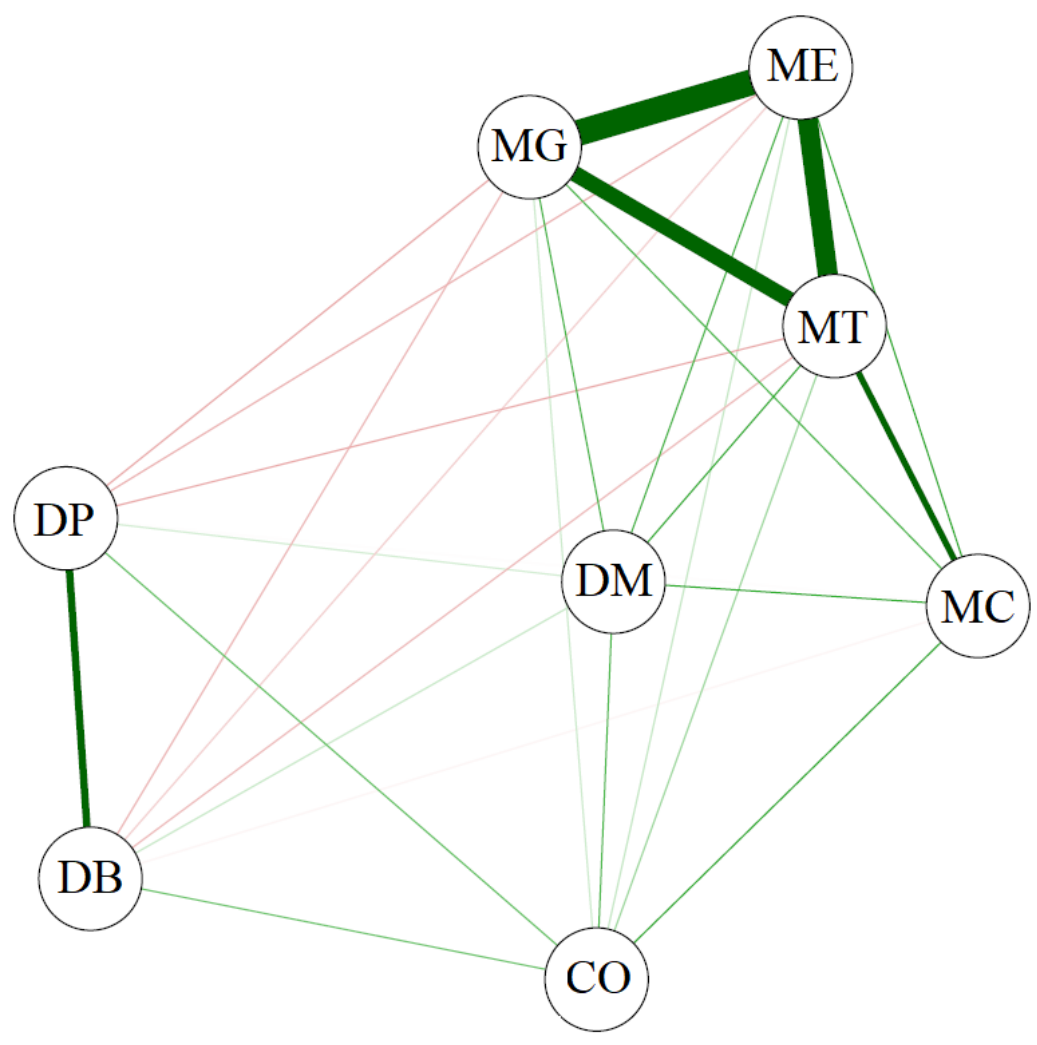

Fonte: Autores.

A massa total da espiga se relacionou negativamente com o diâmetro da base e diâmetro da ponta da espiga. Estas correlações evidenciam a deficiência do desenvolvimento de grãos nessas duas extremidades da espiga, interferindo na produtividade e peso total. Pois o diâmetro de espiga está estreitamente relacionado com enchimento de grãos e número de fileiras de grãos por espiga, que também é influenciado pelo genótipo (Ohland et al., 2005). Nas análises feitas por Santos et al. (2018), observou-se que o comprimento das espigas influenciou diretamente na produção de grãos e causou efeito indireto no diâmetro da espiga.

Analisando a rede correlações acima, pode-se constatar a interação positiva entre o diâmetro da ponta e o diâmetro da base. Da mesma forma, a massa de grãos está correlacionada com a massa total. Ambos os atributos possuem uma forte ligação, exaltando que ambos atributos trabalham diretamente para alta produtividade e desenvolvimento da espiga.

Os resultados obtidos através da análise de trilha, Figura 4, ressaltam efeitos diretos (primeiro grau de correlação) e indiretos (de segundo grau de correlação) entre os atributos estudados. Os efeitos significativos positivos estão relacionados à cor verde. Os efeitos não significativos, em cor vermelha. Utilizando da ferramenta que é a Análise de trilha é possível fazer a 
partição desses coeficientes de correlação dos diferentes atributos, servindo para evidenciar os efeitos diretos e indiretos na produtividade. (Nirupama \& Marker, 2020).

Figura 4 - Resultado da análise de trilha entre os atributos estudados, sendo a massa da espiga (ME) a variável primária, comprimento (CO), diâmetro da base (DB), diâmetro do meio (DM), diâmetro da ponta (DP), massa da casca (MC), massa do grão (MG), massa da espiga (ME), massa total (MT) e r (coeficiente de determinação da análise de cada atributo).

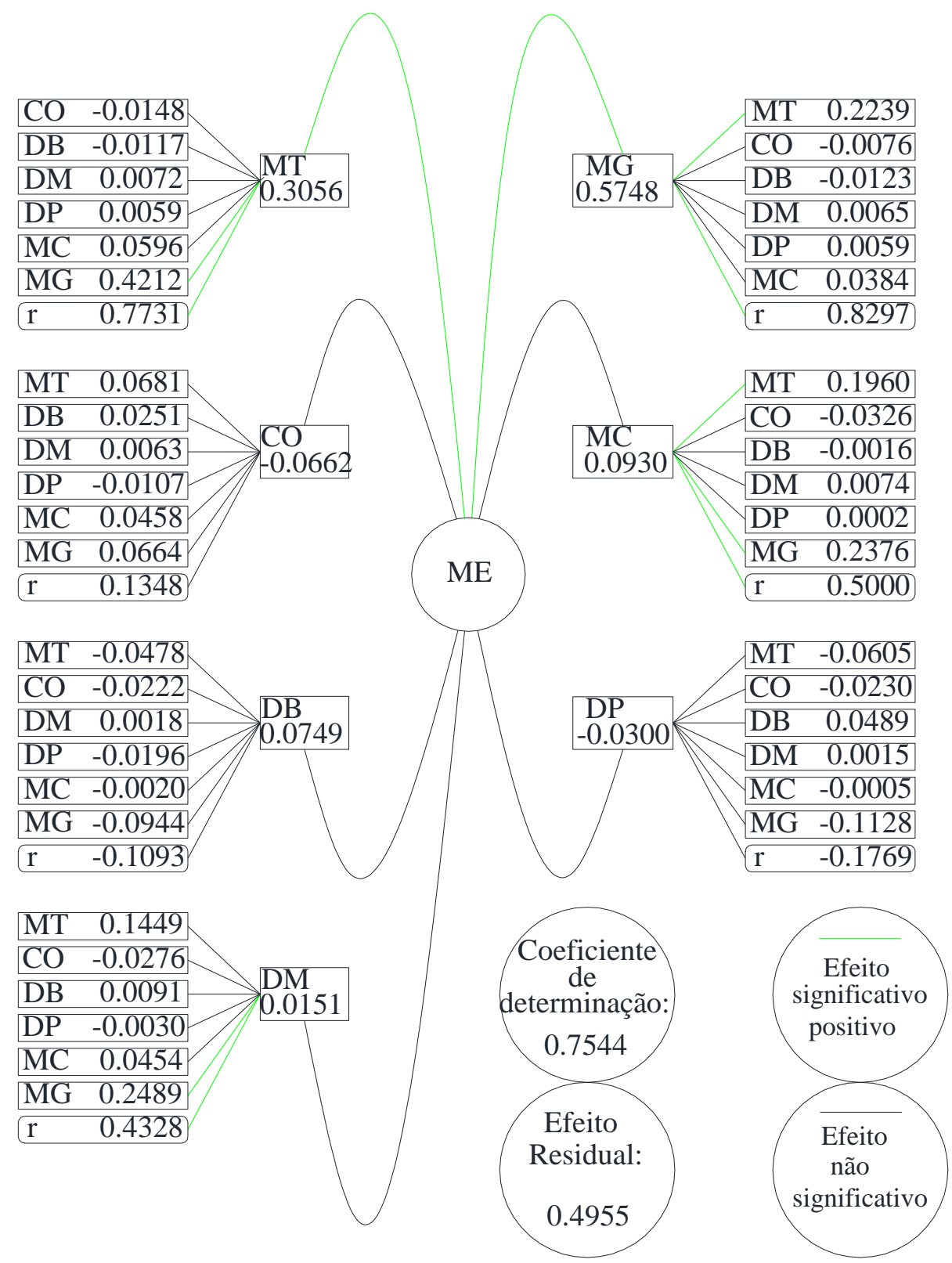

Fonte: Autores.

Pela análise de trilha, foi possível observar, de forma direta, que os atributos massa total da espiga (MT) e massa de grãos da espiga (MG), foram os atributos que melhor representam a massa da espiga (ME), apresentando valores de correlações positivas e significativas de 0,3056 e 0,5748 respectivamente.

De forma indireta, observamos que a massa total da espiga (MT), influencia significativamente a massa dos grãos (MG). Outra verificação indireta foi à relação positiva entre diâmetro médio da espiga (DM) e a massa de grãos (MG) indicando que espigas de maior diâmetro são as que possuem maior massa de grãos. 
Foi obtido um coeficiente de determinação de $0,7544 \%$, o que culmina afirmar que a cada 100 espigas de milho cerca de 75 delas podemos estimar a produtividade para massa de espiga, avaliando a massa total ou a massa de grãos.

Entriger et al. (2014), nas análises de trilha relacionadas ao efeito direto e indireto na produção de milho superdoce, verificou que o volume dos grãos e o volume da espiga são os que mais causam efeito para o peso médio das espigas, o que pode influenciar positivamente na produção de milho.

\section{Considerações Finais}

De forma direta, que os atributos massa total da espiga e massa de grãos da espiga, foram os atributos que melhor representam a massa da espiga.

De forma indireta, observamos que a massa total da espiga, influencia significativamente a massa dos grãos da espiga.

Sugere-se mais estudos nesta área, pois a estatística multivariada pode agregar muitos conhecimentos na cultura do milho e por isso estudos com outros atributos como químicos podem ajudar no melhor entendimento da produção da cultura.

\section{Agradecimentos}

Ao Centro Tecnológico de Agricultura Familiar de Parauapebas (CETAF), a Universidade Federal Rural da Amazônia (UFRA, Parauapebas, PA) e a Universidade Federal do Maranhão (UFMA, Chapadinha, MA). O desenvolvimento deste trabalho contou com apoio da Coordenação de Aperfeiçoamento de Pessoal de Nível Superior - Brasil (CAPES) - Código de Financiamento 001. E ao apoio do Conselho Nacional de Desenvolvimento Científico e Tecnológico (CNPq), pelas bolsas concedidas aos autores.

\section{Referências}

Eliseu Alves, E., Souza, G. S., Garagorry, F. L. (2019). A evolução da produtividade do milho. Revista de Economia e Sociologia Rural, 37(1), 77-96.

Bhering, L. L. (2017). Rbio: A Tool For Biometric And Statistical Analysis Using The R Platform. Crop Breeding and Applied Biotechnology, 17, 187-190. CONAB (2020)- Companhia Nacional de Abastecimento, 7(12). Décimo segundo levantamento. file://C:/Users/55989/Downloads/GrosZsetembroZresumo.pdf Cruz, C. D. (2013). Genes: A Software Package for Analysis in Experimental Statistics and Quantitative Genetics. Acta Scientiarum: Agronomy, 35, 271-276. EMBRAPA (2019) Empresa Brasileira de Pesquisa Agropecuária. Milho - Caracterização e Desafios Tecnológicos, Série desafios do agronegócio brasileiro (NT2).

EMBRAPA (2018) Empresa Brasileira de Pesquisa Agropecuária -. Sistema Brasileiro declassificação de solos. Brasília, DF: EMBRAPA.

Entringer, G. C., Santos, P. H. A. D., Vettorazzi, J. C. F., Cunha, K. S. da, Pereira, M. G. (2014). Análise de correlação e trilha para componentes da produção de milho superdoce. Revista. Ceres, Viçosa, 61(3), 356-361. http://dx.doi.org/10.1590/S0034-737X2014000300009

Favarato, L. F., Souda, J. L., Galvão, J. C. C., Souza, C. M., Guarconi, R. C., Balbino, J. M. S. (2016). Crescimento e produtividade do milho-verde sobre diferentes coberturas de solo no sistema plantio direto orgânico. Bragantia, 75(4), 497-506. http://seicom.pa.gov.br/kitmineracao/estatistica-municipal/regiaodo-carajas/Parauapebas.pdf.

Fernandes, J. D., Chaves, L. H. G., Monteiro Filho, A. F., Vasconcelos, A., Silva, J. R. P. (2017). Crescimento e produtividade de milho sob influência de parcelamento e doses de nitrogênio. Revista Espacios, 38(8). <https://www.revistaespacios.com/a17v38n08/17380829.html

Moreira, J. N., Silva, P. S. L., Silva, K. M. B., Dombroski, J. L. D. e Castro, R. S. (2010). Effect of detasseling on baby corn, green ear and grain yield of two maize hybrids. Horticultura Brasileira, 28, 406-411. http://dx.doi.org/10.1590/S0102 05362010000400005

Nirupama, T., \& Marker, S. (2020). Variação genética e inter-relação entre produtividade de grãos e seus componentes em milho (Zea mays L.). Journal of Pharmacognosy and Phytochemistry, 9(4), 717-720.

Ohland, R. A. A., Souza, L. C. F., Hernani, L. C., Marchetti, M. E., Gonçalves, M. C. (2005). Culturas de cobertura do solo e adubação nitrogenada no milho em plantio direto. Ciência Agrotécnica, 29, 538-544.

Pereira, A. S., Shitsuka, D.M., Parreira, F.J., Shitsuka, R. (2018). Metodologia da pesquisa científica. [e-book]. Santa Maria. Ed. UAB/NTE/UFSM. https://repositorio.ufsm.br/bitstream/handle/1/15824/Lic_Computacao_MetodologiaPesquisaCientifica.pdf?sequence=1. 
Research, Society and Development, v. 10, n. 1, e8010110832, 2021

(CC BY 4.0) | ISSN 2525-3409 | DOI: http://dx.doi.org/10.33448/rsd-v10i1.10832

Pinho, L. de, Paes, M. C. D., Almeida, A. C. de, Costa, C. A. da (2008). Características físicas e físico-químicas de cultivares de milho-verde produzidos em sistemas de cultivo orgânico e convencional. In: Embrapa Milho e Sorgo-Artigo em anais de congresso (ALICE). https://www.alice.cnptia.embrapa.br/bitstream/doc/491285/1/Caracteristicas fisicas.pdf

Santos, N. C. B., Carmo, S. A., Mateus, G. P., Komuro, L. K., Pereira, L. B., Souza, L. C. D de. (2015). Características agronômicas e de desempenho produtivo de cultivares de milho-verde em sistema orgânico e convencional. Semina: Ciências Agrárias, 36(3), suplemento 1, 1807-1822. http://www.uel.br/revistas/uel/index.php/sema grarias/article/view/13662>

Santos, W. F. dos, Vaz, P. C. P., Haesbaert, F. M., Ferreira, T. P. S., Sodré, L. F., Soares, L. B., Pereira, J. S. (2008). Analise de trilha em genótipos de milho no sul do Tocantis. Tecnologia \& Ciência Agropecuária, 12(3), 49-52.

Shikha, K., Shahi, J. P., Singh, S. (2020). Path coefficient analysis in maize (Zea mays L.) hybrids. Journal of Pharmacognosy and Phytochemistry, 9(2), 278282.

Vieira, M. A., Camargo, M. K. Daros, E., Zagonel, J., Koehler, H. S. (2010). Cultivares de milho e população de plantas que afetam a produtividade de espigas verdes. Acta Scientiarum. Agronomy, 32(1), 81-86. 